\title{
The pathology of autoimmune haemolytic anaemia
}

\author{
R J Sokol, D J Booker, R Stamps
}

\section{Introduction}

Autoimmune haemolytic anaemia (AIHA) can be defined as a reduced haemoglobin concentration, resulting from a shortened red cell lifespan, caused by autoantibodies directed against antigens on the patient's erythrocytes. Although AIHA is usually considered to be a well defined clinical syndrome, the more closely cases are examined the more obvious it becomes that severe anaemia is one extreme of a fundamental disturbance of immune homeostasis; at the other end of the spectrum are those in whom erythrocyte autoantibodies are the only abnormality found. The degree of haemolysis can vary considerably and as it often occurs in the absence of anaemia, we prefer the term autoimmune haemolysis (AIH). Detecting its presence often causes enormous difficulties, particularly if the condition is mild or in patients with chronic disorders or serious conditions where the effects of haemorrhage, treatment, and blood transfusion, as well as other causes of anaemia, have to be considered. In such circumstances AIH is not the main problem and confirmatory investigations will probably not be carried out. The

Table 1 Classification of 1834 patients with AIH, based on serological findings and disease association

\begin{tabular}{|c|c|c|c|c|}
\hline Condition & \multicolumn{2}{|c|}{ Warm AIH Cold AIH } & \multirow{3}{*}{ 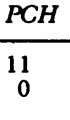 } & \multirow{3}{*}{$\begin{array}{l}\text { Mixed AIH } \\
\begin{array}{c}82 \\
0\end{array}\end{array}$} \\
\hline Idiopathic AIH & 617 & 344 & & \\
\hline \multirow{2}{*}{\multicolumn{5}{|c|}{$\begin{array}{l}\text { Neoplasia } \\
\text { Lymphoid neoplasms }\end{array}$}} \\
\hline & & & & \\
\hline Chronic lymphocytic leukaemia & 63 & 13 & 0 & 0 \\
\hline Acute lymphoblastic leukaemia & 1 & 4 & 0 & 0 \\
\hline Non-Hodgkin's lymphoma & 32 & 22 & 0 & 8 \\
\hline Angioimmunoblastic lymphadenopathy & 1 & 1 & 0 & 0 \\
\hline Myeloma & 4 & 1 & 0 & 0 \\
\hline Macroglobulinaemia & 2 & 3 & 0 & 0 \\
\hline Thyinoma & 1 & 0 & 0 & 0 \\
\hline Hodgkin's disease & 10 & 4 & 0 & 4 \\
\hline Ovarian tumours & 4 & 0 & 0 & 0 \\
\hline Carcinoma (non-ovarian) & 67 & 23 & 0 & 6 \\
\hline Acute non-lymphoid leukaemias & 5 & 4 & 0 & 0 \\
\hline Chronic myeloid leukaemia & 5 & 1 & 0 & 1 \\
\hline Myelofibrosis & 12 & 0 & 0 & 3 \\
\hline Myelodysplastic syndromes & 23 & 4 & 0 & 3 \\
\hline Other neoplasms & 3 & 2 & 0 & 0 \\
\hline \multicolumn{5}{|l|}{ Infection } \\
\hline Pneumonia-Mycoplasma & 0 & 29 & 0 & 1 \\
\hline Pneumonia-"viral" and unspecified & 2 & 13 & 0 & 1 \\
\hline Infectious mononucleosis & 0 & 6 & 0 & 0 \\
\hline Infectious hepatitis & 1 & 1 & 0 & 0 \\
\hline Tuberculosis & 0 & 1 & 0 & 0 \\
\hline Syphilis & 0 & 0 & 1 & 0 \\
\hline Infection-unspecified & 13 & 11 & 7 & 3 \\
\hline \multicolumn{5}{|l|}{ Collagen diseases } \\
\hline Systemic lupus erythematosis & 17 & 8 & 0 & 3 \\
\hline Rheumatoid arthritis & 34 & 9 & 0 & 3 \\
\hline Polyarteritis nodosa & 1 & 0 & 0 & $\mathbf{0}$ \\
\hline \multicolumn{5}{|l|}{ Other immune based and miscellaneous disorders } \\
\hline Ulcerative colitis & 19 & 1 & 0 & 1 \\
\hline Thyrotoxicosis & 3 & 1 & 0 & 1 \\
\hline Myxoedema & 1 & 0 & 0 & 0 \\
\hline Chronic active hepatitis & 2 & 0 & 0 & 0 \\
\hline Pernicious anaemia & 7 & 1 & 0 & 0 \\
\hline Diabetes mellitus & 8 & 3 & 0 & 0 \\
\hline Sarcoidosis & 1 & 0 & 0 & 0 \\
\hline Myasthenia gravis & 1 & 0 & 0 & 0 \\
\hline AIH associated with pregnancy & 22 & 15 & 0 & 1 \\
\hline AIH associated with chronic renal failure & 29 & 12 & 0 & 6 \\
\hline
\end{tabular}

PCH: paroxysmal cold haemoglobinuria.

Regional Blood Transfusion Centre, Longley Lane, Sheffield S5 7JN R Sokol R Stamps Correspondence to: Dr R J Sokol

Accepted for publication 30th March 1992 above points should be borne in mind when considering published findings which have so far tended to favour reports of patients with obvious haemolysis and those cases with interesting disease or drug associations.

For this article, we have selected some aspects of the pathology of AIH which are considered to be of current interest, namely classification, the concept of secondary $\mathrm{AIH}$, incidence, and factors which influence red cell destruction. We have related them to our own experiences of 1834 patients referred either because AIH was suspected or because erythrocyte autoantibodies were causing difficulties in blood grouping and cross-matching. The patients were seen over a 10 year period from 1 January 1982 to 31 December 1991 and were drawn from a population of roughly 4.7 million people living in an area of $16500 \mathrm{~km}^{2}$.

\section{Classification and the concept of second- ary autoimmune haemolysis}

The 1834 patients were classified according to serology and disease association (table 1$).^{12}$ As well as the traditional warm and cold autoantibody types, a separate category of mixed AIH is included where both warm and cold autoantibodies are present and their reactions are such that both are deemed capable of causing haemolysis. ${ }^{3}$ The distribution of cases by serological group is shown in table 2 .

The concept of secondary AIH is complicated. It may mean that the association with another disease occurs more often than can be explained by chance alone (for example, lymphoid neoplasms, systemic lupus erythematosus, Mycoplasma infections); or that the AIH resolves when the associated disease is corrected (for example, some ovarian neoplasms); or that the two conditions are different parts of a complex immunologically mediated multisystem disorder (such as ulcerative colitis); or that there may be a combination of these factors. In other situations it can be more difficult to judge whether the occasional association of AIH with a relatively common disorder, such as acute myeloid leukaemia, pernicious anaemia, cirrhosis, carcinoma, rheumatoid arthritis, thyroid disease, diabetes mellitus and certain infections, is clinically important or whether this should be

Table 2 Serological distribution of 1834 patients with AIH

\begin{tabular}{lc}
\hline Autoantibody type & Number (\%) \\
\hline Warm & $1151(62 \cdot 8)$ \\
Cold & $537(29 \cdot 3)$ \\
Cold agglutinin disease & $19(1 \cdot 0)$ \\
PCH (warm + cold) & $127(6 \cdot 9)$ \\
\hline
\end{tabular}


Incidence of $A I H$ per risk, related to age at presentation. The early childhood peak of cold AIH (arrow) is largely due to patients with $\mathrm{PCH}$. 100000 of population at

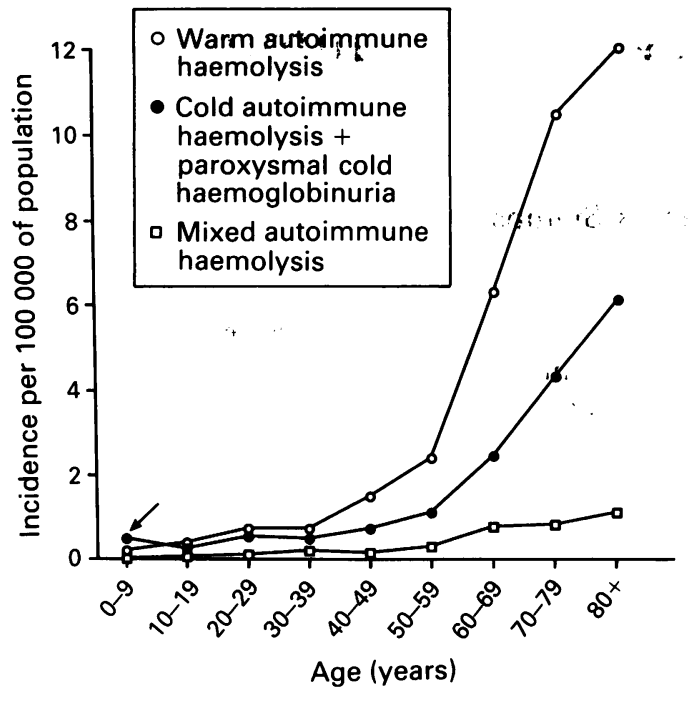

regarded as a chance occurrence. These considerations (and the accuracy of diagnosis on the referral form) should be borne in mind when considering table 1 , which classes $43 \%$ of the cases as secondary. One recently recognised association is that of the myelodysplastic syndromes (table $1^{4}$ ); now that these disorders have been more clearly defined, ${ }^{5}$ the association is increasingly being recognised . Myelodysplastic syndromes did not feature in a large series of patients with AIH in $1981,{ }^{1}$ but in $199113 \%$ of all samples tested were from individuals with this diagnosis.

\section{Incidence}

The incidence of AIH per 100000 of the population at risk, related to age at presentation, was calculated for the 1834 patients (table 1). The results show that, except for a childhood peak of cold AIH, there is a general increase in incidence throughout life, with a dramatic rise occurring after 50 (figure). The figures equate with incidences of about 1 in 25000 , overall, and 1 in 41000 for warm $\mathrm{AIH}$; the latter is greater than the usually quoted minimal annual incidence of 1 in 80000 for this group. ${ }^{6}$ The difference is probably due to improvement in recognising mild and compensated forms. Table 3 gives the serological profiles of the children and adolescents and shows that the early childhood peak of cold AIH (figure) is largely due to patients with paroxysmal cold haemoglobinuria $(\mathrm{PCH})$ caused by Donath-Landsteiner antibodies. Eleven of the 19 patients with this diagnosis were under 5 years old (table 3 ). AIH is more common in females, even when sex differences in the general population are taken into account; the male:female ratio in our patients was $1: 1 \cdot 3$.

Table $3 \mathrm{AIH}$ in childhood and adolescence

\begin{tabular}{lllll}
\hline Age (years) & Warm AIH & Cold AIH & $P C H^{*}$ & Mixed AIH \\
\hline $0-4$ & 8 & 7 & 11 & 1 \\
$5-9$ & 2 & 9 & 1 & 0 \\
$10-15$ & 6 & 1 & 0 & 1 \\
\hline
\end{tabular}

^Secondary in seven patients ("Infection-unspecified" in table 1)
Factors influencing immune mediated red cell destruction

In over $80 \%$ of patients with AIH erythrocyte destruction is extravascular and involves red cells coated with antibody or C3b, or both, reacting with mononuclear phagocytes via specific receptors. Less frequently, haemolysis is intravascular and results from complement being fully activated or, more controversially, through the coated erythrocytes interacting with receptors on lymphoid cells or granulocytes. Receptors consist of heterogeneous groups of glycoproteins; in the case of IgG, for example, three distinct biochemical entities have been defined with differing properties and effector cell expression ${ }^{7}-\mathrm{Fc} \gamma \mathrm{RI}$ is found only on mononuclear phagocytes, but Fc $\gamma \mathrm{RII}$ and Fc $\gamma$ RIII are also present on granulocytes and certain lymphocyte fractions. ${ }^{8}$ Many factors interact in a complex manner to induce red cell destruction. We intend to consider the activity of the mononuclear phagocyte and other cellular systems, the characteristics of the target antigens, the autoantibody response and complement in this article.

THE MONONUCLEAR PHAGOCTYE SYSTEM Immune haemolysis is induced by attachment of bound immunoglobulin or complement to specific macrophage receptors; adherence leads to erythrocyte damage by antibody dependent cellular cytotoxicity (ADCC) and by erythrophagocytosis, incomplete engulfment leaving a non-phagocytosed portion which becomes a rigid spherocyte and is prematurely destroyed in the spleen. Whether ADCC or erythrophagocytosis is the prime mechanism remains to be determined, though both cause considerable haemolysis in vivo. The amount of cell bound antibody seems to be important; with low amounts erythrophagocytosis becomes predominant, the level at which this occurs being much lower for IgG3 antibodies than for IgG1. Assessment of mononuclear phagocyte-red cell interactions is rarely carried out in patients with $\mathrm{AIH}$ as a routine. Most previous investigations have used peripheral blood monocytes (rather than the tissue macrophages which have the major role in vivo) and have shown that red cells from patients with active warm type AIH had increased adherence, rosetting, and phagocytosis per monocyte compared with those from normal subjects. The reactions were further enhanced where complement was detected on the red cells in addition to IgG.

The degree of mononuclear phagocyte activation has an important effect on red cell destruction. Increased activity occurs in certain conditions, including AIHA and various infections ${ }^{9}$; in AIHA, autologous monocytes showed enhanced rosetting and erythrophagocytosis compared with normal monocytes exposed to the same IgG coated red cells. The most consistent increase in activity was seen when the red cells were coated with both IgG and complement. AIHA has been reported following viral infections, vaccination, and immunisation, and one might speculate that these events tipped the balance to overt hae- 
molysis in patients who had small quantities of IgG already on their cells by increasing mononuclear phagocyte activity. ${ }^{9}$ In vitro an increase in rosette formation has been noted during the course of viral infections, and in experimental studies increased clearance of IgG sensitised red cells was found in animals infected with Bacille Calmette-Guérin. ${ }^{9}$

Decreased mononuclear phagocyte activity can also occur. For example, $15 \%$ of patients taking methyl dopa developed IgG autoantibodies to red cells yet only $0.5 \%$ showed active haemolysis.' Studies using radiolabelled red cells suggested that methyl dopa suppressed mononuclear phagocyte function in most patients and that where this did not occur, the cells were lysed. When patients with methyl dopa induced autoantibodies were followed up sequentially, significant in vitro monocyte erythrophagocytosis was seen only during periods of haemolysis. In another example, antibody coated red cells, which were rapidly destroyed in all normal subjects, survived normally in some patients with systemic lupus erythematosus (SLE); it was suggested that immune complexes (DNA:anti-DNA) were saturating the macrophage Fc receptors and this would explain why certain individuals with SLE whose red cells are coated with autoantibody do not experience haemolysis. ${ }^{9}$ A reduction in the number of monocyte $\mathrm{Fc} \gamma$ receptors following glucocorticoid treatment has been reported in patients with AIH and in normal volunteers. In the former group rosette formation, which was evident in untreated patients, was usually absent in those taking more than $30 \mathrm{mg}$ of prednisolone a day. ${ }^{2}$

IMMUNE DESTRUCTION OF ERYTHROCYTES

MEDIATED BY LYMPHOID CELLS AND GRANULOCYTES Although the role of lymphoid cells and granulocytes in immune mediated haemolysis is controversial, ${ }^{2}$ there have been suggestions that in patients with AIH significant red cell destruction can be caused by lymphocytes and, compared with normal individuals, that such patients have more aggressive killer cell activity. In vitro, killer or null cells, which possess receptors for IgG and C3, can induce ADCC which is almost as efficient as that promoted by monocytes and is similarly more effectively mediated by IgG3 antibodies than by IgG1.

Neutrophil granulocytes also carry Fc receptors for IgG, although they normally show little cytotoxicity towards antibody coated red cells. However, considerable activity may be seen in granulocytes during infections and this may in part explain the increased severity of AIH at these times. Granulocyte erythrophagocytosis can be quite prominent in patients with $\mathrm{PCH}^{2}$

\section{THE TARGET ANTIGENS}

The quantity and distribution of the target antigens also have an important effect on immune mediated haemolysis, and recent studies in patients with warm type AIHA have shown a wide variety of antigen sites on the red cell membrane. Serological specificity within the $\mathrm{Rh}$ system is common and in a recent investigation, eluted autoantibodies from more than $25 \%$ of cases reacted with the same polypeptides as those identified with specific anti-Rh monoclonal antibodies. ${ }^{10}$ In other studies the autoantibodies reacted with band 3 , the main membrane glycoprotein, ${ }^{11}$ or had anti-phospholipid activity. ${ }^{12}$ In cases showing anti-Gerbich specificity the antigenic determinants were identified on the $\beta$ sialoglycoproteins, ${ }^{1314}$ while autoantibodies showing antiScl specificity reacted with a membrane antigen of 60-65 kilodaltons. ${ }^{15}$ There have been similar findings in canine AIHA where autoantibodies recognised a combination of 29 and 42 kilodalton peptides, possibly equivalent to the human $\mathrm{Rh}$ complex, as well as an autoantigen having the same molecular mass as band $3 .^{16}$

Exposure of the T cryptantigens can occur as a result of microbial infection; this leads to polyagglutinability of the red cells and, in some cases, to severe intravascular haemolysis due to the interaction with natural anti- $T$ causing complement activation. ${ }^{17}$

Antigen depression is occasionally found in patients with AIHA; in such cases the autoantibodies can masquerade as alloantibodies. This is a rare phenomenon but seems to occur most frequently in relation to the Kell ${ }^{18}$ and Gerbich $^{1419}$ blood group systems. Depression of the $\mathrm{Rh}$ antigens has also been reported ${ }^{182}$; large amounts of autoantibody were demonstrated in the serum but the direct antiglobulin test was negative. The autoantibody seemed to have destroyed most of the red cells and only the small proportion with a reduced $R h$ antigen status could survive in vivo. The antigen depression, which was transient, was thought to represent a protective mechanism against haemolysis. ${ }^{1820}$ Patients with cold haemagglutinin disease due to anti-I or $\mathrm{i}$ red cells coated solely with $\mathrm{C} 3 \mathrm{~d}, \mathrm{~g}$ have a normal lifespan. The erythrocytes are protected against premature destruction because the complement binding and Ii antigen sites are in close proximity. Bound $\mathrm{C} 3 \mathrm{~b}$, which can effect red cell destruction, is rapidly converted to C $3 \mathrm{~d}, \mathrm{~g}$, which sterically inhibits the attachment of more autoantibody and hence fixation of further active $\mathrm{C} 3 \mathrm{~b}$ on to the cells. The result is a dual red cell survival curve in most patients, a population of rapidly destroyed cells being present in conjunction with one having a normal lifespan. C3d,g protection does not extend to cases where the autoantibodies have other specificities. ${ }^{2}$

AMOUNT OF ANTIBODY BOUND TO THE RED CELLS AND EFFECT OF IMMUNOGLOBULIN CLASS AND SUBCLASS

The immune response in AIH is more complex than commonly supposed, and multiple immunoglobulin classes and subclasses, as well as complement components, are frequently bound to the red cells. ${ }^{2122}$ To assess the role and interrelations of individual factors, studies must be performed using sensitive methods and strictly defined population groups. In one such investigation, where only non-complement binding IgG1 autoantibodies were 
Table 4 Pattern of IgG subclasses eluted from red cells in 426 samples from 304 patients with warm autoantibodies

\begin{tabular}{lc}
\hline IgG subclasses & Number \\
\hline 1 & 273 \\
2 & 1 \\
3 & 5 \\
$1+2$ & 31 \\
$1+3$ & 31 \\
$1+4$ & 22 \\
$2+4$ & 1 \\
$1+2+3$ & 18 \\
$1+2+4$ & 18 \\
$1+3+4$ & 6 \\
$1+2+3+4$ & 20 \\
\hline
\end{tabular}

Table 5 Immunoglobulin classes bound to red cells in 590 samples from 404 patients with warm autoantibodies

\begin{tabular}{lc}
\hline Immunoglobulins & Number \\
\hline IgG & 372 \\
IgG + IgM & 137 \\
IgG + IgA & 34 \\
IgG + IgM + IgA & 47 \\
\hline
\end{tabular}

present, haemolysis was determined predominantly by the quantity of antibody coating the cells-the larger the amount the greater the degree of haemolysis, with a haemolytic threshold at about 1000 molecules of IgG per cell. $^{23}$

The distribution and effects of IgG subclasses in AIH were studied in concentrated red cell eluates from 304 patients on 426 occasions. ${ }^{22}$ Multiple subclasses were found in $147(34.5 \%)$ of the samples (table 4 ), a higher incidence than in previous reports. ${ }^{24}$ This was probably because examining eluates is more sensitive than testing the red cells directly. ${ }^{22}$ IgG1 was by far the most common, being present in $419(98 \%)$ samples overall and in 273 out of the 279 where only one subclass was identified (table 4). This pattern of results precluded comparing individual subclasses, but did permit examination of the effects of multiple versus single subclass coating. As multiple IgG subclasses were significantly associated with the presence of multiple immunoglobulin classes (which have a haemolytic effect in their own right ${ }^{21}$ ), further analyses were carried out using samples where IgG alone coated the red cells. In these circumstances multiple subclasses were significantly associated with higher amounts of cell bound IgG ( $>800 \mathrm{~mol} / \mathrm{red}$ blood cell) and more cases had haptoglobin concentration of $<0.1 \mathrm{~g} / 1$. Reduced haptoglobulin concentration were not significantly associated with the presence of IgG3 unless the cases with multiple immunoglobulins were included in the analysis. Studies which reported that overt AIH occurred in virtually all cases where IgG3 was

Table 6 Patients with warm type red cell autoantibodies: relation between presence of IgM coating and serum haptoglobin concentration

\begin{tabular}{|c|c|c|}
\hline & \multicolumn{2}{|c|}{ Immunoglobulins coating red cells } \\
\hline & $\operatorname{Ig} G+\operatorname{Ig} M$ & $\operatorname{Ig} G$ \\
\hline $\begin{array}{l}\text { Proportion with haptoglobins }<0 \cdot 1 \mathrm{~g} / 1 \\
\text { Number of samples in total population } \\
\chi^{2} \\
95 \% \text { confidence interval for difference between proportions }\end{array}$ & $\begin{array}{l}0.44 \\
18\end{array}$ & $\begin{array}{l}0.09 \\
150 \\
\\
58\end{array}$ \\
\hline
\end{tabular}

thighly significant $(p<0.0005)$ at 1 degree of freedom present, ${ }^{2425}$ did not take into account any effects due to associations with multiple immunoglobulin classes and subclasses.

The IgG subclasses have different interactions with mononuclear phagocytes which are thought to be the result of their varying affinity for Fc receptors, rather than there being specific receptors for each subclass. ${ }^{9}$ IgG3 antibodies have a higher affinity for mononuclear phagocyte receptors than IgG1 antibodies, with IgG2 and IgG4 binding much less efficiently still. This can be shown in vitro where monocyte reactions with IgG3 coated erythrocytes are much more rapid than with IgG1, rosette formation is greater, and fewer molecules are required to initiate erythrophagocytosis.

The effects of immunoglobulin class in warm type AIH were investigated in 590 samples from 404 patients. ${ }^{21}$ Using the very sensitive enzyme linked antiglobulin test, the red cells of 218 (37\%) samples were found to be coated with increased amounts of IgM or IgA in addition to IgG (table 5). Compared with cases where red cells were coated with IgG alone, the presence of multiple immunoglobulins was significantly, associated with cases where larger amounts of IgG ( $>800 \mathrm{~mol} /$ red blood cell), multiple IgG subclasses, IgG3, and $C 3 d$ were bound to the cells, and where haptoglobin concentrations were $<0 \cdot 1 \mathrm{~g} / 1$. The latter association was still significant when cells were coated with low concentrations of IgG ( $<400 \mathrm{~mol} / \mathrm{red}$ blood cell) of a single subclass (IgG1 of $98 \%$ of cases), and was not due to the presence of cell bound complement. The study concluded that multiple immunoglobulin coating, even when undetected by agglutination methods, was a major cause of haemolysis. Although it was part of a more generalised autoimmune response and acted with other factors such as the quantity of bound IgG, the IgG subclass pattern and complement, it also had an important haemolytic effect in its own right. ${ }^{21}$

Cases of severe AIHA have been reported where IgA was the sole immunoglobulin bound to the red cells, but in our experience using enzyme-linked antiglobulin tests, other immunoglobulin classes have usually also been present in subagglutinating amounts. IgA class autoantibodies probably induce haemolysis via Fc receptors in the same way as IgG. Specific receptors for IgA have been demonstrated on monocytes, ${ }^{24}$ and spherocytosis has been reported in patients with IgA coated red cells, splenic sequestration occurring when such cells were labelled with ${ }^{51} \mathrm{Cr}$ and used for survival studies. ${ }^{25}$ In vitro, IgA antibodies have been shown to augment the effect of IgG induced $\mathrm{ADCC}{ }^{26}$

It is still controversial whether IgM autoantibodies can cause immune mediated haemolysis other than by activating complement, and if they do, how this is possible, as macrophages are said to lack specific receptors for IgM. ${ }^{9}$ Nevertheless, there are reports of AIHA that seemed to be associated with non-complement activating IgM autoantibodies, ${ }^{27}$ and we have felt for some time that IgM coating acts 
synergistically with IgG in effecting red cell destruction.

To provide further information on this point, we examined the records of the 1834 patients (table 1) and selected those with only warm autoantibodies and where the red cells were coated with $<800 \mathrm{~mol} / \mathrm{red}$ blood cell of IgGl, but not with other IgG subclasses, complement, or IgA. Cohorts were distinguished by the presence or absence of cell bound $\operatorname{IgM}$ and analysed for their association with haptoglobin concentrations of $<0.1 \mathrm{~g} / \mathrm{l}$ and $\geqslant 0.5 \mathrm{~g} / \mathrm{l}$ by a $\chi^{2}$ procedure described previously. ${ }^{21} 22$ One hundred and sixty eight cases were included in the study; their distribution is shown in table 6, together with the results of the statistical analysis. The significantly higher $(p<0.0005)$ proportion of cases in the IgG + IgM group with haptoglobin concentrations of $<0.1 \mathrm{~g} / 1$, compared with the IgG group, provides substantial evidence for warm IgM autoantibodies being able to induce red cell destruction independently of any effect through complement. Elucidating the mechanisms of such haemolysis will be an important and fascinating area for future investigations.

THE ROLE OF COMPLEMENT

Complement mediated haemolysis is usually extravascular. Activation is often triggered, but regulatory inactivators operate at several points on the complement cascade causing inhibition, usually at the level of $\mathrm{C} 3$, so that red cells circulate with $\mathrm{C} 3 \mathrm{~b}$ or $\mathrm{iC} 3 \mathrm{~b}$ bound on their surface. Destruction is then by phagocytosis (or through the production of spherocytes) and occurs mostly in the liver macrophages. Although the binding of $\mathrm{C} 3 \mathrm{~b}$ coated cells to macrophage CR1 or CR3 receptors is very efficient, maximal adherence and phagocytic capacities (the former considerably greater than the latter) limit the amount of destruction. Many erythrocytes are engulfed immediately, but others slowly return to the circulation due to cleavage of the fixed $\mathrm{C} 3 \mathrm{~b}$ by naturally occurring regulatory factors to produce $\mathrm{C} 3 \mathrm{~d}, \mathrm{~g}$ (which is further reduced in vitro to C3d). Macrophages do not react efficiently with $\mathrm{C} 3 \mathrm{~d}, \mathrm{~g}$ in vivo and, as already mentioned, the red cells may now survive normally, even though the direct antiglobulin test is strongly positive. Erythrocytes coated solely with $\mathrm{C} 3 \mathrm{~b}$ do not undergo ADCC, but complement coating significantly reduces the number of IgG molecules needed to initiate this process, the augmentation persisting after degradation of $\mathrm{C} 3 \mathrm{~b}$ to $\mathrm{C} 3 \mathrm{~d} .^{28}$

There is some evidence that red cell bound complement has a quantitative effect in relation to haemolysis. This is difficult to assess in vitro as the $\mathrm{C} 3 \mathrm{~b}$ coated cells have either been destroyed or the $\mathrm{C} 3 \mathrm{~b}$ converted to $\mathrm{C} 3 \mathrm{~d}, \mathrm{~g}$. Nevertheless, it is thought that about $550-800$ bound $\mathrm{C} 3 \mathrm{~b}$ molecules are required to activate the hepatic clearance mechanism, and in one study most patients with more than $1100 \mathrm{C} 3 \mathrm{~d}$ molecules per red cell had an associated haemolytic anaemia ${ }^{29}$ - presumably because of a proportional relation with the number of $\mathrm{C} 3 \mathrm{~b}$ molecules originally bound to the cells.
Intravascular haemolysis is rare and only occurs if activation of red cell bound complement proceeds to completion: it is seen in less than $20 \%$ of patients with AIHA, but is the most efficient method of red cell destruction and can produce severe anaemia. Antibodies which trigger this process are mostly of IgM class, although it can also be caused by some warm IgG1 and IgG3 antibodies; the classic IgG example, however, is the cold-reacting Donath-Landsteiner antibody. In spite of IgM class antibodies being better at activating complement than IgG, those found in the cold agglutinin syndrome are far less efficient than Donath-Landsteiner antibodies. As a result, severe intravascular haemolysis, a common feature in $\mathrm{PCH}$, is not obvious in most patients with cold haemagglutinin disease. ${ }^{9}$ This may be due to differences in affinity of the two types of antibody; cold reacting IgM autoantibodies rapidly leave the red cells when the temperature increases to $37^{\circ} \mathrm{C}$ (the optimal temperature for complement activation), whereas Donath- Landsteiner antibodies stay bound for longer and are thus better able to trigger activation.' Intravascular haemolysis occurs about 10 times more frequently in children and this seems to parallel an increase in AIHA secondary to infection. Possibly, autoantibodies stimulated by viruses or bacteria are more efficient at activating complement, or perhaps the pathogens make the red cell more susceptible to its action. ${ }^{9}$ Infection is an important factor in the development of $\mathrm{PCH}^{2}$ and it is of interest that although this type of haemolysis is rare, accounting for only about $1 \%$ of all our patients (table 1 ), in children $26 \%$ of cases were in this group (table 3 ).

We thank the Statistical Information Unit of the Trent Regional Health Authority for providing population details, the Department of Medical Illustration, Northern General Hospital, Sheffield, for their expert help, and Mrs M E Grayson for secretarial assistance.

1 Sokol RJ, Hewitt S, Stamps BK. Autoimmune haemolysis: an 18 year study of 865 cases referred to a regional transfusion centre. Br Med F 1981;282:2023-7.

2 Sokol RJ, Hewitt S. Autoimmune haemolysis: a critical review. CRC Crit Rev Oncol Hematol 1985;4:125-54.

3 Sokol RJ, Hewitt S, Stamps BK. Autoimmune haemolysis: mixed warm and cold antibody type. Acta Haematol 1983;69:266-74.

4 Sokol RJ, Hewitt S, Booker DJ. Erythrocyte autoantibodies, autoimmune haemolysis, and myelodysplastic syndromes. $f$ Clin Pathol 1989;42:1088-91.

5 Bennett JM. Classification of the myelodysplastic syndromes. Clin Haematol 1986;15:909- 23.

6 Petz LD, Garratty G. Acquired immune hemolytic anemias. New York: Churchill Livingstone 1980;26-63.

7 Schreiber AD, Gomez F, Levinson AI, Rossman MD. The Fc $\gamma$ receptors on human macrophages Transfus Med Rev 1989;III:282-9.

8 Engelfriet CP. The immune destruction of red cells. Transfus Med 1992;2:1-6.

9 Garratty G. Factors affecting the pathogenicity of red cell auto- and alloantibodies. In: Nance SJ, ed. Immune destruction of red blood cells. Arlington, VA: American Association of Blood Banks, 1989:109-69.

10 Barker RN, Casswell KM, Reid ME, Sokol RJ, Elson CJ Identification of autoantigens in autoimmune haemolytic anaemia by a non-radioisotope immunoprecipitation method. Br $\mathcal{Y}$ Haematol 1992;82:126-32.

11 Victoria EJ, Pierce SW, Branks MJ, Masouredis SP. IgG red blood cell autoantibodies in autoimmune hemolytic anaemia bind to epitopes on red blood cell membrane band 3 glycoprotein. $尹$ Lab Clin Med 1990;115:74-88.

12 Arvieux J, Schweizer B, Roussel B, Colomb MG. Autoimmune haemolytic anaemia due to anti-phospholipid antibodies. Vox Sang 1991;61:190-5.

13 Reid ME, Vengelen-Tyler V, Shulman I, Reynolds MV. Immunochemical specificity of autoanti-Gerbich from 
two patients with autoimmune haemolytic anaemia and concomitant alteration in the red cell membrane sialogycoprotein $\beta$. Br f Haematol 1988;69:61-6.

14 Poole J, Reid ME, Banks J, Liew YW, Addy J, Longster G. Serological and immunochemical specificity of a human autoanti-Gerbich-like antibody. Vox Sang 1990;58 $287-91$.

15 Owen I, Chowdhury V, Reid ME, Poole J, Marsh JCW Hows JM. Autoimmune hemolytic anaemia associated with anti-Scl. Transfusion 1992;32:173-6.

16 Barker RN, Gruffydd-Jones TJ, Stokes CR, Elson CJ. Identification of autoantigens in canine autoimmune haemolytic anaemia. Clin Exp Immunol 1991;85:33-40.

17 Levene C, Levene NA, Buskila D, Manny N. Red cell Levene C, Levene NA, Buskila D, Manny N. Red
polyagglutination. Transfus Med Rev 1988;2:176-85.

18 Issitt PD. Applied blood group serology. 3rd edn. Miami: Montgomery Scientific Publications, 1985:301-536.

19 Göttsche B, Salama A, Mueller-Eckhardt C. Autoimmune haemolytic anaemia associàted with an IgA autoantiGerbich. Vox Sang 1990;58:211-4.

20 Issitt PD, Gruppo RA, Wilkinson SL, Issitt CH. Atypical presentation of acute phase, antibody-induced haemolytic anaemia in an infant. $\mathrm{Br} \mathcal{F}$ Haematol 1982;52:537-43.

21 Sokol RJ, Hewitt S, Booker DJ, Bailey A. Red cell autoantibodies, multiple immunoglobulin classes, and autoimmune haemolysis. Transfusion 1990;30:714-7.

22 Sokol RJ, Hewitt S, Booker DJ, Bailey A. Erythrocyte autoantibodies, subclasses of IgG and autoimmune hae- molysis. Autoimmunity 1990;6:99-104

23 van der Meulen FW, de Bruin HG, Goosen PCM, et al. Quantitative aspects of the destruction of red cells sensitised with IgGl autoantibodies; an application of flow cytofluorometry. $\mathrm{Br} \mathcal{F}$ Haematol 1980;46:47-56.

24 Engelfriet CP, Overbeeke MAM, von dem Borne AEG Kr. Autoimmune hemolytic anaemia. Semin Hematol 1992;22:3-12.

25 Engelfriet CP, von dem Borne AEG, Beckers D, et al. Immune destruction of red cells. In: Bell CA, ed. $A$ seminar on immune mediated red cell destruction. Chicago: American Association of Blood Banks, 1981:93-130.

26 Shen L, Fanger MW. Secretory IgA antibodies synergiz with IgG in promoting ADCC by human polymorphonuclear cells, monocytes, and lymphocytes. Cell Immuno

27 Salama A, Mueller-Eckhardt C. Autoimmune haemolytic anaemia in childhood associated with non-complement binding IgM autoantibodies. Br 7 Haematol 1987;65: 67-71.

28 Kurlander RJ, Rosse WF, Logue GL. Quantitative influence of antibody and complement coating of red cells on monocyte-mediated cell lysis. $f$ Clin Invest 1978; 61:1309-19.

29 Freedman J, Ho M, Barefoot C. Red blood cell-bound C3d in selected hospital patients. Transfusion 1982, in s2:515-20. 